OPEN ACCESS

Edited by:

Johnny Padulo,

University of Milan, Italy

Reviewed by:

Claudio Pizzolato,

Griffith University, Australia

Sina David,

Vrije Universiteit

Amsterdam, Netherlands

*Correspondence:

Charlotte Menez

charlotte.menez@orthodynamica.com

Specialty section:

This article was submitted to Biomechanics and Control of Human

Movement,

a section of the journal Frontiers in Sports and Active Living

Received: 01 July 2020 Accepted: 11 November 2020 Published: 16 December 2020

Citation:

Menez C, L'Hermette $M$ and Coquart J (2020) Orthotic Insoles Improve Gait Symmetry and Reduce Immediate Pain in Subjects With Mild Leg Length Discrepancy. Front. Sports Act. Living 2:579152. doi: 10.3389/fspor.2020.579152

\section{Orthotic Insoles Improve Gait Symmetry and Reduce Immediate Pain in Subjects With Mild Leg Length Discrepancy}

\author{
Charlotte Menez ${ }^{1,2 *}$, Maxime L'Hermette ${ }^{1}$ and Jeremy Coquart ${ }^{1}$ \\ ${ }^{1}$ Normandie Univ, UNIROUEN, CETAPS, Rouen, France, ${ }^{2}$ Orthodynamica Center, Mathilde Hospital 2, Rouen, France
}

Background: Mild leg length discrepancy can lead to musculoskeletal disorders; however, the magnitude starting from which leg length discrepancy alters the biomechanics of gait or benefits from treatment interventions is not clear.

Research question: The aim of the current study was to examine the immediate effects of orthotic insoles on gait symmetry and pain on mild leg length discrepancy according to two groups of the leg length discrepancy (i.e., LLD $\leq 1 \mathrm{~cm}$ vs. LLD $>1 \mathrm{~cm}$ ).

Methods: Forty-six adults with mild leg length discrepancy were retrospectively included and classified into two groups ( $G_{\llcorner L D \leq 1 \mathrm{~cm}}$ or $G_{\llcorner L D>1 \mathrm{~cm}}$ ). All subjects underwent routine $3 \mathrm{D}$ gait analysis with and without orthotic insoles. The symmetry index was calculated to assess changes in gait symmetry between the right and left limbs. Pain was rated without (in standing) and with the orthotic insoles (after $30 \mathrm{~min}$ of use) on a visual analog scale.

Results: There was a significant improvement in the symmetry index of the pelvis in the frontal plane $(p=0.001)$ and the ankle in the sagittal plane $(p=0.010)$ in the stance with the orthotic insoles independent from the group. Pain reduced significantly with the orthotic insoles independently from the group $(p<0.001)$.

Significance: Orthotic insoles significantly improved gait symmetry in the pelvis in the frontal plane and the ankle in the sagittal plane, as well as pain in all subjects (both LLD $\leq 1 \mathrm{~cm}$ and LLD $>1 \mathrm{~cm}$ ) suggesting that it may be appropriate to treat even mild leg length discrepancy.

Keywords: leg length inequality, gait analysis, foot orthoses, musculo skeletal diseases, podiatry, walking

\section{INTRODUCTION}

Leg length discrepancy (LLD) can be either caused by anatomical deformities originating from true differences in the bony structures of the lower limb, or it may be functional, resulting from abnormal lower limb movements (Khamis and Carmeli, 2018). The diagnosis (Brady et al., 2003), classification (Gurney, 2002), and treatment (Campbell et al., 2018) of LLD remain controversial among both researchers and clinicians. Some authors classify discrepancies $\leq 2.0 \mathrm{~cm}$ as mild (Moseley, 1996), while others consider discrepancies of up to $3.0 \mathrm{~cm}$ as mild (Reid and Smith, 1984; McCaw and Bates, 1991; Gurney, 2002; Brady et al., 2003; Campbell et al., 2018). These classifications are intended to guide practitioners in the treatment of LLD, but there is much 
disagreement in the literature as to the magnitude from which LLD requires treatment. It has been suggested that orthotic insoles (OIs), shoe lifts, or other clinical interventions to equalize leg length should be considered for LLD $\geq 1.0 \mathrm{~cm}$ (White et al., 2004), or even between 0.5 and $1.0 \mathrm{~cm}$ (Khamis and Carmeli, 2018). However, other authors are more conservative, suggesting that below $2 \mathrm{~cm}$, no treatment is required (Moseley, 1996).

The lack of consensus regarding the need to treat mild LLD stems from the fact that there is no real agreement as to the biomechanical effects of a mild LLD on lower limb and spinal joints during walking (Friberg, 1982; Kaufman et al., 1996; Goel et al., 1997; Resende et al., 2016; Khamis and Carmeli, 2018). Many studies (Friberg, 1984; Walsh et al., 2000; Seeley et al., 2010; Murray and Azari, 2015; Resende et al., 2016; Tallroth et al., 2017) have reported that even mild LLD can cause lower limb biomechanical disorders. For example, one study (Walsh et al., 2000) found that compensatory strategies and asymmetrical gait occurred from $1.0 \mathrm{~cm}$ of LLD induced by foot lifts (from 1 to $5 \mathrm{~cm}$ high). Similar results were reported in an earlier study (Kaufman et al., 1996) in which the authors also hypothesized that individuals with even mild LLD use compensatory functional mechanisms to attenuate the effect of the LLD, presumably to minimize displacement of the center of body mass. However, the effect of mild LLD on gait has not been unequivocally demonstrated (Resende et al., 2016; Khamis and Carmeli, 2018).

Mild LLD, including LLD $\leq 1 \mathrm{~cm}$, has been associated with an increased risk of knee osteoarthritis (Harvey, 2010) and scoliosis (Specht and De, 1991), both of which are frequently associated with low back pain (Defrin et al., 2005). Mild LLD is therefore frequently treated with the aim of preventing the development of such secondary pathologies. OIs are the most frequently used treatment (Kendall et al., 2014) likely because they are noninvasive, inexpensive, and readily available (Defrin et al., 2005). Despite the widespread use of OI, their impact on gait kinematics (Bandy and Sinning, 1986; Goel et al., 1997; Bangerter et al., 2019) and pain (Defrin et al., 2005; Golightly et al., 2007) has been little studied in subjects with mild anatomical LLD. Recently, Menez et al. (2020) evaluated the effect of OI on gait kinematics and low back pain in subjects with mild LLD. They found that changes in gait symmetry varied and was specific across individuals; however, low back pain decreased in all subjects after the use of OI. However, mild LLD is commonly not treated in patients with low back pain (Junk et al., 1992; Mannello, 1992; Defrin et al., 2005). Moreover, mild LLD is frequently found in the adult population (Junk et al., 1992; Mannello, 1992), and the correction of LLD $\leq 1 \mathrm{~cm}$ remains insufficiently incorporated into the treatment of low back pain (Junk et al., 1992; Mannello, 1992; Defrin et al., 2005), with many clinicians continuing to overlook the potential impact of mild LLD (Defrin et al., 2005). There is disagreement about the correct treatment and the magnitude of LLD (Gurney, 2002). Indeed, for White et al. (2004), OIs

Abbreviations: $G_{L L D} \leq 1 \mathrm{~cm}$, Group Leg Length Discrepancy $\leq 1 \mathrm{~cm} ; G_{L L D>1 \mathrm{~cm}}$, Group Leg Length Discrepancy > $1 \mathrm{~cm}$; LLD, Leg Length Discrepancy; OI, Orthotic Insoles; SI, Symmetry Index; STROBE, STrengthening the Reporting of OBservational studies in Epidemiology. to equalize leg length should be considered in subjects with LLD $\geq 1 \mathrm{~cm}$, whereas Khamis and Carmeli (2018) go further, suggesting that even mild LLD between 0.5 and $1 \mathrm{~cm}$ should be treated. This recent position of Khamis and Carmeli (2018) is in contradiction with other previous studies suggesting that mild LLD is naturally compensated and should therefore be neglected without any treatment being considered. Apart from the definite interest on pain, the evidence still appears to be limited in terms of kinematics. Therefore, we have searched for additional information to support the interest or not to treat real $\mathrm{LLD} \leq 1.0 \mathrm{~cm}$.

Studies are therefore needed to clearly identify the magnitude of LLD from which OI improves gait kinematics and/or pain.

It seems that LLD causes asymmetry in the locomotion of the lower limbs, leading to pain, with a disruption of normal biomechanical function. The functional alterations increase biomechanical disorders, asymmetrical gait, low back pain, and/or other pain, and may even promote the development of associated pathologies such as osteoarthritis of the hip or knee. OI is a treatment often used in podiatry to try to reduce biomechanical asymmetries and pain. We hypothesize that OI can reduce the asymmetries and associated pain in subjects with mild and very mild LLD during walking.

The primary aim of this study was therefore to evaluate the immediate effects of OI on gait symmetry and pain according to the degree of mild LLD (i.e., $L L D \leq 1 \mathrm{~cm}$ vs. $L L D>1 \mathrm{~cm}<3 \mathrm{~cm}$ ). The secondary aim was to analyze the specific effects of OI on lower limb joint kinematics.

\section{MATERIALS AND METHODS}

\section{Subjects}

This 18-month, retrospective study, included data from consecutive patients with mild LLD followed with a prescription for OI from their General Practitioner. The study was written according to the STrengthening the Reporting of OBservational studies in Epidemiology (STROBE) statement (Von Elm et al., 2014). Data from all patients meeting the following criteria were analyzed retrospectively. Only adults (aged between 18 and 70 years) were included. None previously had correction of their LLD. The diagnosis of mild LLD $(\leq 3.0 \mathrm{~cm})$ was confirmed by a chiropodist using an accepted clinical procedure (Khamis and Carmeli, 2017). The cutoff of $3.0 \mathrm{~cm}$ was selected according to Campbell et al. (2018). Subjects were excluded if they were obese (body mass index $\geq 30 * \mathrm{~kg} \mathrm{~m}^{-2}$ ) or if they had a history of surgery, lower limb injury, or neuromuscular or vascular pathology in the last 6 months (information routinely collected during the clinical examination). Subjects were classified into one of two groups, according to the magnitude of the LLD: $G_{L L D} \leq 1 \mathrm{~cm}$ and $G_{L L D>1 \mathrm{~cm}}$ in line with the studies of Seeley et al. (2010) and Defrin et al. (2005).

All the subjects included had undergone routine care, including biomechanical gait analysis with and without the OI as is the usual procedure in our center.

All procedures performed in this study were in accordance with the ethical standards of the institutional and national research committee and with the 1964 Helsinki declaration 
and its later amendments, and written informed consent was obtained from each subject (Ethical committee number: IRB00012476-2020-15-07-61).

\section{Procedure}

The chiropodist performed a clinical examination that included measurement of the LLD, rating of pain, and collection of sociodemographical and anthropometrical data (i.e., sex, age, body mass, height, and body mass index).

LLD was measured using a direct clinical method (mean of two measurements of the distance between the anterior superior iliac spine and the medial malleolus, while lying in a supine position, using a tape measure). This direct method has already been shown to be valid and reliable in comparison with computed tomography scan (Jamaluddin et al., 2011; Neelly et al., 2013). The mean of three measures was used (Beattie et al., 1990). For this study, the intra-tester reproducibility for the measurement with the tape measure was good, with an ICC of 0.809 .

Subjects were referred by a physician for causes of acute muscular affection in low back or lower limb. Even if in this study all causes of pain were retained, we were only interested in one pain per subject with LLD (the most painful condition). The origin of the main cause of pain was investigated, and its intensity was assessed using a visual analog scale. Subjects were asked to stand for $5 \mathrm{~min}$ (Golightly et al., 2007) and then to rate their immediate pain on a visual analog scale graded from 0 (no pain) to 10 (maximal pain), as proposed by Hayashi et al. (2015). The location of pain was noted for each subject (low back, hip, knee, or ankle). The average of all these pains was calculated without and with the OI.

Gait analysis was then performed using a Qualisys proreflex motion analysis system (Qualisys $\mathrm{AB}^{\circledR}$, Göteborg, Sweden) with 10 infrared video cameras at a sampling frequency of $120 \mathrm{~Hz}$. Twenty reflective markers were fixed to the anatomical landmarks: the two most anterior and the two most posterior margins of the iliac spines, the most lateral prominence of the greater trochanter and of the lateral femoral epicondyle, the proximal tip of the head of the fibula, the most anterior border of the tibial tuberosity, the lateral prominence of the lateral malleolus, the Achilles tendon insertion on the calcaneous, and the dorsal margins of the 1st and 5th metatarsal heads, in accordance with Leardini et al. (2007) (Figure 1). The same investigator positioned the markers on all subjects. A static calibration was carried out before the gait trials in order to generate a neutrally aligned reference "IOR lower body" model with respect to the coordinate system of each segment. Subjects wore their usual shoes without OI, which was necessary because the aim was to put them in a walking condition to which they are accustomed. After $10 \mathrm{~min}$ of familiarization with the environment by walking around the room, the subjects were instructed to walk at a self-selected speed along the $15 \mathrm{~m}$ walkway. Four trials were recorded, and gait cycles performed in the center $10 \mathrm{~m}$ of the walkway were used in the analysis. Each trial consisted of five gait cycles making a total of 20 gait cycles for each subject.

The chiropodist made the OI using a thermoforming process: the OIs were first warmed before being molded using a pillow

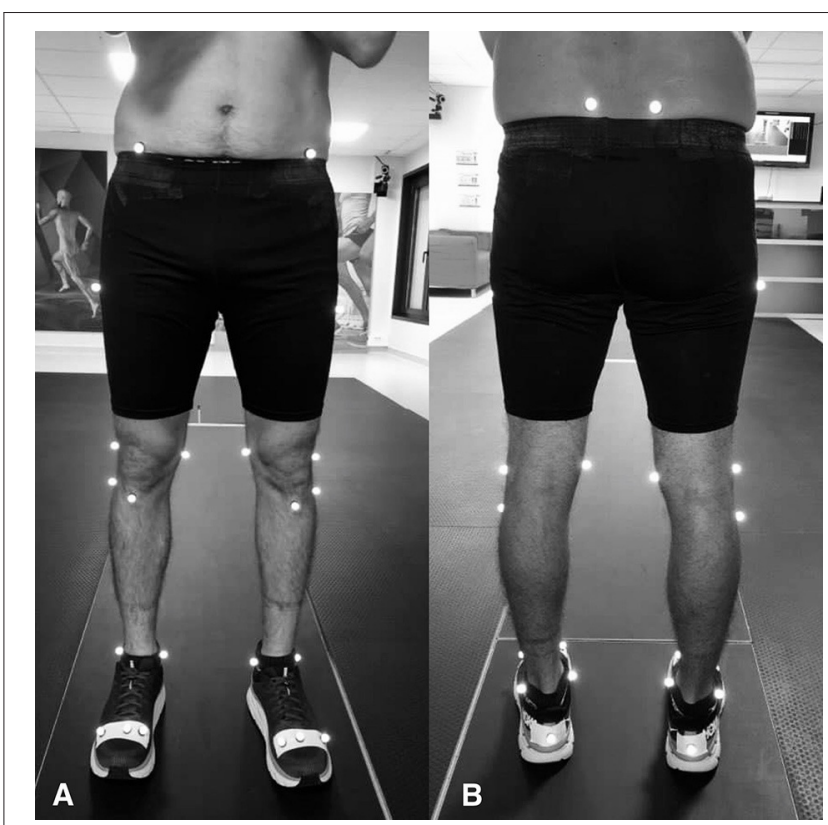

FIGURE 1 | Istituti Ortopedici Rizzoli (IOR) lower body marker set-anterior (A) and posterior (B) views (Leardini et al., 2007).

mold to obtain the foot imprint, as recently described by Menez et al. (2020). The materials used in the OIs were ethinyl vinyl acetate, resin, and polyethylene. Once the OIs were molded, they were further shaped to effectively counteract the effects of the LLD and rebalance the kinematics of walking. The whole procedure took $30 \mathrm{~min}$. They were made according to the therapeutic needs of the subjects, with a heel lift incorporated into the OI of the short leg. The heel lifts were partially corrective of the LLD, to $50 \%$, and were shaped from the calcaneus to the Chopart joint (Figure 2). This corrective strategy is used empirically by the pedicurist-chiropodist for all subjects with LLD. At the end of the process, the pedicurist-chiropodist checked the impact of the OI by examining the iliac crest position in the frontal plane while the subject was standing.

The subjects then wore the OIs for 30 min during which time they walked within the center (familiarization phase). After this time, the kinematic analysis and pain rating were repeated with the OI.

The 3D displacement of the markers was processed, and kinematic variables were calculated using Visual3D software (C-Motion ${ }^{\circledR}$, Germantown, United States) with inverse kinematics approach. The anatomical reference frames for each segment were defined according to Cappozzo et al. (1995), consistent with the international recommendations ( $\mathrm{Wu}$ and Cavanagh, 1995; Wu et al., 2002). Standard coordinate systems (Grood and Suntay, 1983) were attributed to each joint. Joint angles were defined by rotations occurring about the three joint coordinate axes. For the hip and knee joints, flexion/extension was defined as the relative rotation about a fixed medio-lateral axis $(\mathrm{Z})$, internal/external rotation as the relative rotation about a fixed vertical axis $(\mathrm{Y})$, and 

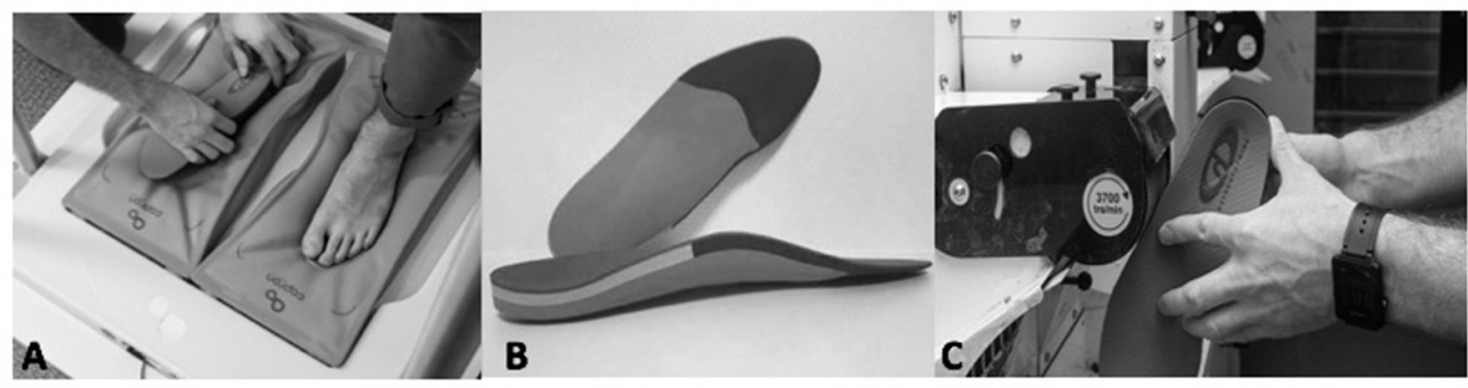

FIGURE 2 | Thermoforming the orthotic insoles (A). Orthotic insoles in ethinyl vinyl acetate, resin, and polyethylene (B). Further shaping the orthotic insoles (C)

abduction/adduction about a "floating" anterior-posterior axis $(\mathrm{X})$. For the ankle joint, these three rotations were defined, respectively, as dorsiflexion/plantarflexion, inversion/eversion, and abduction/adduction. Pelvic tilt (anterior-posterior), rotation, and obliquity (lateral tilt) were calculated using the same convention, with a virtual joint defined between the laboratory global reference frame and the pelvis. In addition to the standard calculation of absolute angles, the offset was calculated by subtracting the corresponding static posture angle from all joint rotations (Leardini et al., 2007).

Total joint range of motion was calculated from peak values (maxima and minima). Then the mean range of motion was calculated from the 20 gait cycles for each joint rotation for each limb. A symmetry index (SI) was calculated using the equation described by Robinson et al. (1987), where:

$$
\begin{aligned}
\mathrm{SI}= & \{(\text { value } \mathrm{RJ}-\text { value } \mathrm{LJ}) \div[0.5 \times(\text { value } \mathrm{RJ} \\
& + \text { value } \mathrm{LJ})]\} \times 100
\end{aligned}
$$

In this equation, RJ corresponds to the right joint range of motion value and LJ to the left joint range of motion value. The SI yields a percentage value, which in the case of perfect symmetry is equal to $0 \%$.

\section{Statistical Analysis}

Data are reported as means \pm standard deviations. The normality of the distribution of each variable was verified with a Shapiro-Wilk test, and equality of variances was analyzed with a Levene's test.

A Student independent samples $t$-test or Mann-Whitney $U$ test was used to compare the baseline data between groups (i.e., $\mathrm{G}_{\mathrm{LLD} \leq 1 \mathrm{~cm}}$ vs. $\mathrm{G}_{\mathrm{LLD}>1 \mathrm{~cm}}$ ).

A two-way ANOVA with repeated measures was carried out to analyze the effect of the OI on each variable as a function of the group, with the orthosis condition (with/without OI) as the within-subjects factor and the group $\left(G_{L L D} \leq 1 \mathrm{~cm}\right.$ vs. $\left.\mathrm{G}_{\mathrm{LLD}>1 \mathrm{~cm}}\right)$ as the between-subjects factor. Separate ANOVAs were carried out for the longer and shorter legs. Sphericity was verified with a Mauchley test, and if it was not met, the significance of the F-ratios was adjusted according to the Greenhouse-Geisser procedure or the Huyn-Feldt procedure.
TABLE 1 | Sociodemographic, anthropometric characteristics, and pain ratings of

\begin{tabular}{|c|c|c|}
\hline & $G_{L L D \leq 1 \mathrm{~cm}}$ & $G_{L L D>1 \mathrm{~cm}}$ \\
\hline & $n=16$ & $n=30$ \\
\hline Men (\%) & $43.8 \%$ & $53.3 \%$ \\
\hline Age (years) & $33.4 \pm 12.1$ & $35.5 \pm 12.4$ \\
\hline Body mass (kg) & $70.4 \pm 13.1$ & $71.6 \pm 12.2$ \\
\hline Height (m) & $1.74 \pm 0.10$ & $1.73 \pm 0.09$ \\
\hline Body mass index $\left(\mathrm{kg} \mathrm{m}^{-2}\right)$ & $23.2 \pm 3.0$ & $23.8 \pm 2.7$ \\
\hline Leg length discrepancy (mm) & $8.3 \pm 1.4$ & $15.1 \pm 4.0^{\mathrm{a}}$ \\
\hline
\end{tabular}
the subjects included in each group.

${ }^{a}$ Significant difference between groups $(p<0.001)$.

When significant differences were obtained, a Bonferroni posthoc test was conducted to determine where the differences lay.

Statistical significance was set at $p<0.05$, and all analyses were performed with Statistica software (version 10.0, Statsoft ${ }^{\circledR}$, Tulsa, OK, United States).

\section{RESULTS}

A total of 46 subjects with anatomic LLD were included in the study (Table 1). Sixteen subjects had an LLD $\leq 1.0 \mathrm{~cm}$, and 30 had an LLD between 1.0 and $3.0 \mathrm{~cm}$. In 14 cases, the shorter leg was on the left, and in 32 cases, it was on the right. There were no significant between-group differences for sex $(p=0.536)$, age ( $p$ $=0.585)$, body mass $(p=0.775)$, height $(p=0.787)$, body mass index $(p=0.512)$, or pain rating $(p=0.768$; Table 1$)$. All the average normalized kinematic curves for each group $\left(G_{L L D} \leq 1 \mathrm{~cm}\right.$ and $\mathrm{G}_{\mathrm{LD}>1 \mathrm{~cm}}$ ) without and with orthotic insoles during the gait cycle have been added in the Supplementary Material.

\section{Stance Phase}

There was a significant effect of the OI on the SI, with an improvement in the symmetry of pelvic motion in the frontal plane $(p=0.001)$ and ankle motion in the sagittal plane $(p=$ 0.010 ; Table 2). Although, there was a significant effect of the OI on the hip SI in the frontal plane according to the ANOVA $(p=$ 
TABLE 2 | Symmetry index (with joint range of motion) between the longer and shorter legs for the sagittal, frontal, and transverse planes for the pelvis, hip, knee, and ankle with or without orthotic insoles (Ols) in both groups during the stance and swing phases.

\begin{tabular}{|c|c|c|c|c|c|c|c|c|c|}
\hline \multirow[t]{2}{*}{ Phase } & \multirow[t]{2}{*}{ Joint } & \multirow[t]{2}{*}{ Plane } & \multicolumn{2}{|c|}{ Without OI } & \multicolumn{2}{|c|}{ With 이 } & \multirow{2}{*}{$\begin{array}{l}\text { Orthosis } \\
\text { effect } \\
\text { (p value) }\end{array}$} & \multirow{2}{*}{$\begin{array}{c}\text { Group } \\
\text { effect } \\
\text { (p-value) }\end{array}$} & \multirow{2}{*}{$\begin{array}{c}\text { Combined } \\
\text { effect } \\
\text { (p-value) }\end{array}$} \\
\hline & & & $G_{L L D} \leq 1 \mathrm{~cm}$ & $G_{L L D>1 \mathrm{~cm}}$ & $G_{L L D} \leq 1 \mathrm{~cm}$ & $G_{L L D>1 \mathrm{~cm}}$ & & & \\
\hline \multirow[t]{12}{*}{ Stance phase } & Pelvis & $\begin{array}{l}\text { Sagittal } \\
\text { (anterior/posterior tilt) }\end{array}$ & $16.5 \pm 14.1$ & $19.9 \pm 16.3$ & $15.2 \pm 15.2$ & $20.0 \pm 16.6$ & 0.803 & 0.340 & 0.786 \\
\hline & & $\begin{array}{l}\text { Frontal } \\
\text { (upward/downward tilt) }\end{array}$ & $10.8 \pm 8.0$ & $14.4 \pm 8.2$ & $7.1 \pm 6.0$ & $11.2 \pm 7.5$ & $0.001^{*}$ & 0.085 & 0.780 \\
\hline & & $\begin{array}{l}\text { Transverse } \\
\text { (internal/external rotation) }\end{array}$ & $5.6 \pm 6.1$ & $8.1 \pm 7.7$ & $5.6 \pm 4.2$ & $8.3 \pm 13.3$ & 0.974 & 0.296 & 0.949 \\
\hline & Hip & $\begin{array}{l}\text { Sagittal } \\
\text { (flexion/extension) }\end{array}$ & $4.4 \pm 3.6$ & $3.9 \pm 2.8$ & $4.9 \pm 3.4$ & $3.8 \pm 3.1$ & 0.552 & 0.408 & 0.345 \\
\hline & & $\begin{array}{l}\text { Frontal } \\
\text { (adduction/abduction) }\end{array}$ & $15.4 \pm 9.2$ & $13.4 \pm 9.2$ & $10.6 \pm 8.1$ & $12.7 \pm 10.5$ & $0.027^{\star}$ & 0.992 & 0.105 \\
\hline & & $\begin{array}{l}\text { Transverse } \\
\text { (internal/external rotation) }\end{array}$ & $25.6 \pm 23.5$ & $33.6 \pm 25.8$ & $24.6 \pm 23.3$ & $29.6 \pm 23.9$ & 0.434 & 0.344 & 0.633 \\
\hline & Knee & $\begin{array}{l}\text { Sagittal } \\
\text { (flexion/extension) }\end{array}$ & $8.8 \pm 6.1$ & $11.1 \pm 8.3$ & $9.8 \pm 6.8$ & $11.4 \pm 7.1$ & 0.535 & 0.334 & 0.718 \\
\hline & & $\begin{array}{l}\text { Frontal } \\
\text { (adduction/abduction) }\end{array}$ & $24.1 \pm 13.7$ & $26.5 \pm 20.2$ & $22.3 \pm 16.9$ & $30.6 \pm 22.1$ & 0.699 & 0.302 & 0.345 \\
\hline & & $\begin{array}{l}\text { Transverse } \\
\text { (internal/external rotation) }\end{array}$ & $29.2 \pm 24.9$ & $27.0 \pm 18.0$ & $24.3 \pm 24.1$ & $25.6 \pm 18.2$ & 0.270 & 0.936 & 0.538 \\
\hline & Ankle & $\begin{array}{l}\text { Sagittal } \\
\text { (dorsiflexion/plantar flexion) }\end{array}$ & $17.3 \pm 7.3$ & $18.1 \pm 11.5$ & $13.6 \pm 9.5$ & $15.2 \pm 10.8$ & $0.010^{\star}$ & 0.688 & 0.719 \\
\hline & & $\begin{array}{l}\text { Frontal } \\
\text { (inversion/eversion) }\end{array}$ & $24.8 \pm 16.5$ & $25.4 \pm 17.4$ & $26.0 \pm 19.1$ & $24.6 \pm 16.5$ & 0.934 & 0.941 & 0.619 \\
\hline & & $\begin{array}{l}\text { Transverse } \\
\text { (internal/external rotation) }\end{array}$ & $36.8 \pm 25.5$ & $30.9 \pm 22.2$ & $28.8 \pm 22.1$ & $27.8 \pm 19.7$ & 0.115 & 0.564 & 0.487 \\
\hline \multirow[t]{12}{*}{ Swing phase } & Pelvis & $\begin{array}{l}\text { Sagittal } \\
\text { (anterior/postrior tilt) }\end{array}$ & $27.2 \pm 14.8$ & $30.4 \pm 24.7$ & $35.7 \pm 24.0$ & $29.0 \pm 25.2$ & 0.320 & 0.781 & 0.168 \\
\hline & & $\begin{array}{l}\text { Frontal } \\
\text { (upward/downward tilt) }\end{array}$ & $19.3 \pm 12.5$ & $16.9 \pm 10.3$ & $17.4 \pm 10.5$ & $13.9 \pm 9.7$ & 0.054 & 0.342 & 0.646 \\
\hline & & $\begin{array}{l}\text { Transverse } \\
\text { (internal/external rotation) }\end{array}$ & $9.7 \pm 7.4$ & $11.1 \pm 9.3$ & $10.9 \pm 9.0$ & $14.6 \pm 19.1$ & 0.248 & 0.475 & 0.574 \\
\hline & Hip & $\begin{array}{l}\text { Sagittal } \\
\text { (flexion/extension) }\end{array}$ & $5.0 \pm 3.5$ & $5.0 \pm 4.6$ & $5.7 \pm 4.5$ & $5.0 \pm 3.9$ & 0.469 & 0.757 & 0.531 \\
\hline & & $\begin{array}{l}\text { Frontal } \\
\text { (adduction/abduction) }\end{array}$ & $21.4 \pm 22.7$ & $22.1 \pm 20.4$ & $17.5 \pm 17.0$ & $22.2 \pm 17.4$ & 0.334 & 0.634 & 0.309 \\
\hline & & $\begin{array}{l}\text { Transverse } \\
\text { (internal/external rotation) }\end{array}$ & $34.9 \pm 26.4$ & $41.2 \pm 30.7$ & $37.3 \pm 34.4$ & $37.4 \pm 24.8$ & 0.864 & 0.695 & 0.419 \\
\hline & Knee & $\begin{array}{l}\text { Sagittal } \\
\text { (flexion/extension) }\end{array}$ & $3.0 \pm 1.6$ & $3.7 \pm 2.9$ & $3.2 \pm 1.6$ & $3.3 \pm 2.7$ & 0.778 & 0.554 & 0.351 \\
\hline & & $\begin{array}{l}\text { Frontal } \\
\text { (adduction/abduction) }\end{array}$ & $30.9 \pm 23.4$ & $42.1 \pm 27.6$ & $31.9 \pm 18.9$ & $47.4 \pm 35.3$ & 0.509 & 0.083 & 0.649 \\
\hline & & $\begin{array}{l}\text { Transverse } \\
\text { (internal/external rotation) }\end{array}$ & $30.3 \pm 27.0$ & $29.5 \pm 22.5$ & $26.7 \pm 21.6$ & $26.6 \pm 18.3$ & 0.430 & 0.934 & 0.924 \\
\hline & Ankle & $\begin{array}{l}\text { Sagittal } \\
\text { (dorsiflexion/plantar flexion) }\end{array}$ & $14.4 \pm 9.5$ & $15.4 \pm 13.4$ & $13.2 \pm 9.5$ & $15.5 \pm 15.4$ & 0.737 & 0.657 & 0.668 \\
\hline & & $\begin{array}{l}\text { Frontal } \\
\text { (inversion/eversion) }\end{array}$ & $33.1 \pm 19.9$ & $40.8 \pm 31.0$ & $28.4 \pm 18.6$ & $35.7 \pm 31.1$ & 0.294 & 0.299 & 0.968 \\
\hline & & $\begin{array}{l}\text { Transverse } \\
\text { (internal/external rotation) }\end{array}$ & $33.0 \pm 28.0$ & $31.1 \pm 28.3$ & $31.8 \pm 25.9$ & $25.9 \pm 23.1$ & 0.183 & 0.619 & 0.414 \\
\hline
\end{tabular}

*Significant difference $(p<0.05)$.

0.027), the Bonferroni post-hoc test did not show any significant differences between the conditions $(p=0.067)$.

There was a significant effect of group on the kinematics of several joints. On the side of the longer leg, peak hip adduction was greater $(p=0.041)$, and peak downward lateral pelvic tilt $(p=0.035)$ and peak hip abduction were lower $(p=0.044)$ in the $G_{L L D>1 \mathrm{~cm}}$ (Table 3 ). On the side of the shorter leg, peak upward pelvic tilt (Figure 3) was greater $(p=0.011)$, and 
TABLE 3 | Peak stance phase angles of the pelvis, hip, knee, and ankle joints for each leg with and without orthotic insoles (Ols) for both groups.

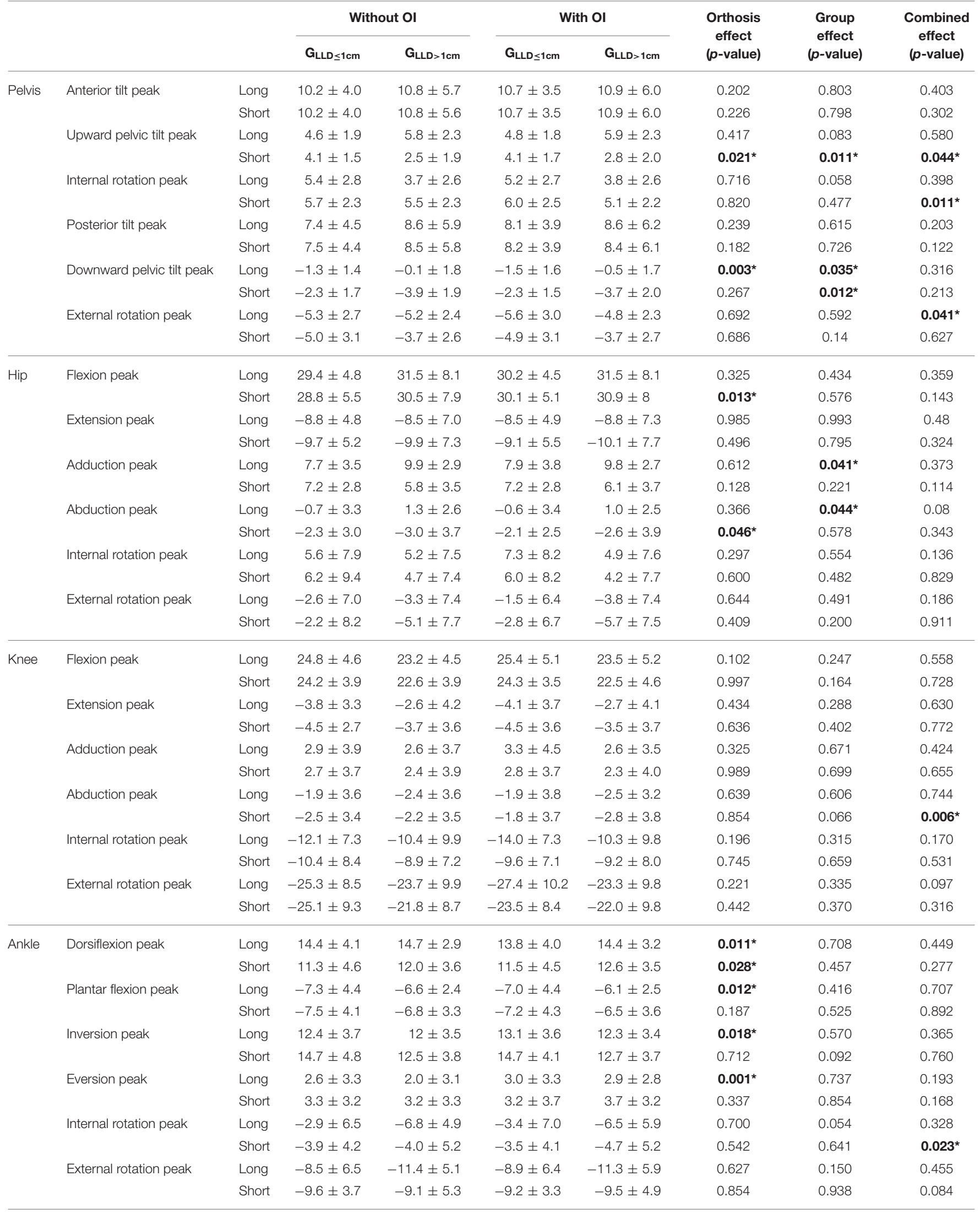

*Significant difference $(p<0.05)$. 


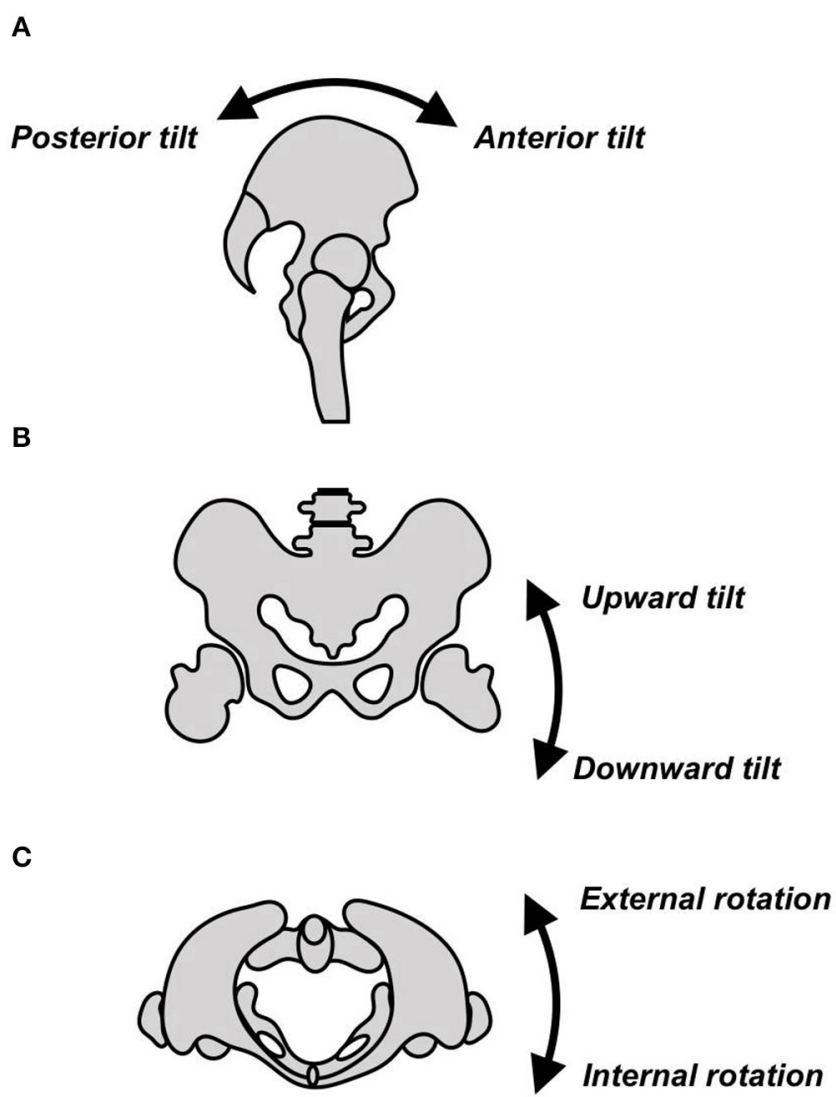

FIGURE $\mathbf{3}$ | Movement of the pelvis in (A) the sagittal plane, (B) the frontal plane, and $(\mathbf{C})$ the transverse plane.

peak downward lateral pelvic tilt was lower $(p=0.012)$ in the $\mathrm{G}_{\mathrm{LLD}} \leq 1 \mathrm{~cm}$.

There was a significant effect of OI on the kinematics of several joints. On the side of the longer leg, peak downward lateral pelvic tilt $(p=0.003)$ and peak ankle inversion $(p=0.018)$ were significantly increased with the OI compared to without the OI. Peak ankle eversion $(p=0.001)$, peak ankle dorsiflexion $(p=0.011)$, and peak ankle plantarflexion $(p=0.012)$ were significantly decreased with the OI (Table 3). On the side of the shorter leg, peak upward lateral pelvic tilt angle $(p=0.021)$, peak hip flexion angle $(p=0.013)$, and peak ankle dorsiflexion angle ( $p=0.028)$ were significantly increased, and peak hip abduction angle $(p=0.046)$ was significantly decreased with the OI.

Although the ANOVA showed an interaction between OI and group for the shorter leg for peak ankle internal rotation ( $p=$ $0.023)$ and peak knee abduction $(p=0.006)$, the Bonferroni posthoc test indicated there were no significant differences between these factors. There was a significant interaction between OI and group for peak upward pelvic tilt on the side of the shorter leg: the Bonferroni post-hoc test indicated that without the OI, peak upward pelvic tilt was greater in the $\mathrm{G}_{\mathrm{LLD} \leq 1 \mathrm{~cm}}(p=0.044)$ than the $\mathrm{G}_{\mathrm{LLD}}>1 \mathrm{~cm}$.
There was a significant interaction between OI and group for peak upward pelvic tilt: the Bonferroni post-hoc test indicated that with the OI, peak upward pelvic tilt increased significantly in the $\mathrm{G}_{\mathrm{LLD}>1 \mathrm{~cm}}(p=0.04)$, compared to without the OI.

\section{Swing Phase}

There was a significant effect of group on the SI for several joints. On the side of the longer leg, peak upward pelvic tilt and peak hip adduction angle $(p=0.007)$ were significantly lower in the $\mathrm{G}_{\mathrm{LLD} \leq 1 \mathrm{~cm}}(p=0.009)$, and downward lateral pelvic tilt was greater $(p=0.013$; Table 4$)$. On the side of the shorter leg, peak external pelvic rotation was significantly greater in the $\mathrm{G}_{\mathrm{LLD}} \leq 1 \mathrm{~cm}(p=0.014)$.

There was a significant effect of OI on the kinematics of several joints. On the side of the longer leg, peak upward pelvic tilt ( $p$ $=0.001)$, peak knee flexion decreased $(p=0.003)$, and peak downward pelvic tilt $(p=0.013)$ increased significantly with the OI (Table 4).

On the side of the shorter leg, there was a significant increase in peak ankle dorsiflexion $(p<0.001)$.

\section{Pain}

There was a significant effect of OI on pain $(p<0.001)$. The pain reduced from $5.9 \pm 1.8$ to $1.7 \pm 2.1$ in $G_{L L D} \leq 1 \mathrm{~cm}$ and from 5.7 \pm 2.6 to $2.0 \pm 2.5$ in $\mathrm{G}_{\mathrm{LLD}>1 \mathrm{~cm}}$. There was no group effect $(p=$ 0.929) (Table 5).

\section{DISCUSSION}

The aim of this study was to evaluate the immediate effect of OI on gait kinematics and pain in subjects with mild LLD according to two groups of the leg length discrepancy.

The results of this study demonstrated that gait symmetry improved with the OI, particularly at the pelvis (frontal plane) and ankle (sagittal plane) during the stance phase of gait, with no between-group differences. Moreover, there was a significant reduction in pain with the OI (with no betweengroup differences). The kinematic results support the findings of a number of studies that showed that even mild LLD can alter the kinematics of gait and cause pain (Perttunen et al., 2004; Defrin et al., 2005; Golightly et al., 2007; Seeley et al., 2010; Khamis and Carmeli, 2018). The results of this study add to this body of knowledge by showing that even LLD $<1 \mathrm{~cm}$ can alter symmetry and cause pain, and that both symmetry and pain can be improved with OI.

The results of this study confirm previous findings that deviations of pelvic motion in the frontal plane are common in LLD (Giles, 1981; Giles and Taylor, 1982; Walsh et al., 2000; Golightly et al., 2007; Jamaluddin et al., 2011; Resende et al., 2016). There was a significant increase in peak pelvic downward lateral tilt on the side of the longer leg with the OI, and a concomitant increase in peak upward lateral tilt on the side of the shorter leg $(p=0.021)$ in both groups with the OI. Similar results have previously been found with the use of OI in subjects with moderate and severe LLD (Bangerter et al., 2019). The present results showed that OIs have a similar effect in mild LLD $\leq 1$ and $>1 \mathrm{~cm}$. The increase in ankle dorsiflexion on the 
TABLE 4 | Peak swing phase angles of the pelvis, hip, knee, and ankle joints for each leg with and without orthotic insoles (Ol) for both groups.

\begin{tabular}{|c|c|c|c|c|c|c|c|c|c|}
\hline & & & \multicolumn{2}{|c|}{ Without OI } & \multicolumn{2}{|c|}{ With OI } & \multirow{2}{*}{$\begin{array}{l}\text { Orthosis } \\
\text { effect } \\
\text { (p-value) }\end{array}$} & \multirow{2}{*}{$\begin{array}{c}\text { Group } \\
\text { effect } \\
\text { (p-value) }\end{array}$} & \multirow{2}{*}{$\begin{array}{c}\text { Combined } \\
\text { effect } \\
\text { (p-value) }\end{array}$} \\
\hline & & & $\mathrm{G}_{\mathrm{LLD} \leq 1 \mathrm{~cm}}$ & $G_{L L D>1 \mathrm{~cm}}$ & $\mathrm{G}_{\mathrm{LLD} \leq 1 \mathrm{~cm}}$ & $G_{L L D>1 \mathrm{~cm}}$ & & & \\
\hline \multirow[t]{12}{*}{ Pelvis } & Anterior tilt peak & Long & $9.9 \pm 4.0$ & $10.5 \pm 5.6$ & $10.4 \pm 3.5$ & $10.5 \pm 5.9$ & 0.295 & 0.826 & 0.242 \\
\hline & & Short & $9.8 \pm 4.2$ & $10.6 \pm 5.7$ & $10.4 \pm 3.6$ & $10.6 \pm 6.1$ & 0.209 & 0.767 & 0.294 \\
\hline & Upward pelvic tilt peak & Long & $0.7 \pm 1.3$ & $2.1 \pm 1.6$ & $0.5 \pm 1.5$ & $1.7 \pm 1.6$ & $0.001^{*}$ & $0.009^{*}$ & 0.175 \\
\hline & & Short & $-0.6 \pm 1.7$ & $-1.7 \pm 2.0$ & $-0.6 \pm 1.7$ & $-1.6 \pm 2.0$ & 0.418 & 0.077 & 0.654 \\
\hline & Internal rotation peak & Long & $4.3 \pm 3.0$ & $3.0 \pm 2.8$ & $4.3 \pm 3.1$ & $3.0 \pm 3.0$ & 0.983 & 0.168 & 0.87 \\
\hline & & Short & $4.6 \pm 2.7$ & $4.5 \pm 2.3$ & $4.8 \pm 3.0$ & $4.2 \pm 2.3$ & 0.473 & 0.615 & 0.101 \\
\hline & Posterior tilt peak & Long & $7.5 \pm 4.5$ & $8.4 \pm 5.7$ & $8.2 \pm 4.0$ & $8.4 \pm 6.1$ & 0.255 & 0.758 & 0.177 \\
\hline & & Short & $7.4 \pm 4.4$ & $8.7 \pm 5.9$ & $8.1 \pm 3.9$ & $8.7 \pm 6.2$ & 0.212 & 0.579 & 0.165 \\
\hline & Downward pelvic tilt peak & Long & $-4.0 \pm 1.5$ & $-2.5 \pm 1.9$ & $-4.1 \pm 1.7$ & $-2.8 \pm 2.0$ & $0.013^{\star}$ & $0.013^{*}$ & 0.127 \\
\hline & & Short & $-4.6 \pm 1.9$ & $-5.8 \pm 2.3$ & $-4.7 \pm 1.7$ & $-5.9 \pm 2.3$ & 0.502 & 0.073 & 0.672 \\
\hline & External rotation peak & Long & $-5.4 \pm 2.3$ & $-5.0 \pm 2.3$ & $-5.5 \pm 2.4$ & $-4.7 \pm 2.2$ & 0.469 & 0.459 & 0.173 \\
\hline & & Short & $-5.1 \pm 2.4$ & $-3.2 \pm 2.2$ & $-4.9 \pm 2.5$ & $-3.2 \pm 2.2$ & 0.617 & $0.014^{\star}$ & 0.425 \\
\hline \multirow[t]{12}{*}{ Hip } & Flexion peak & Long & $31.6 \pm 5.1$ & $33.7 \pm 7.3$ & $31.8 \pm 4.9$ & $33.4 \pm 7.5$ & 0.890 & 0.367 & 0.515 \\
\hline & & Short & $30.4 \pm 5.9$ & $32.1 \pm 7.7$ & $31.3 \pm 5.2$ & $32.5 \pm 8$ & 0.092 & 0.521 & 0.435 \\
\hline & Extension peak & Long & $-5.8 \pm 4.7$ & $-5.7 \pm 6.6$ & $-5.2 \pm 4.6$ & $-5.8 \pm 6.9$ & 0.461 & 0.897 & 0.355 \\
\hline & & Short & $-6.3 \pm 5.5$ & $-6.6 \pm 7.2$ & $-5.7 \pm 5.4$ & $-6.7 \pm 7.5$ & 0.567 & 0.765 & 0.312 \\
\hline & Adduction peak & Long & $1.1 \pm 3.3$ & $3.9 \pm 2.6$ & $1.2 \pm 3.7$ & $3.6 \pm 2.5$ & 0.363 & $0.007^{*}$ & 0.163 \\
\hline & & Short & $-0.1 \pm 2.7$ & $-0.6 \pm 3.6$ & $0.0 \pm 2.3$ & $-0.4 \pm 3.8$ & 0.092 & 0.673 & 0.34 \\
\hline & Abduction peak & Long & $-4.7 \pm 3.4$ & $-2.7 \pm 2.6$ & $-4.4 \pm 3.4$ & $-2.8 \pm 2.6$ & 0.720 & 0.051 & 0.089 \\
\hline & & Short & $-5.6 \pm 2.6$ & $-6.5 \pm 3.4$ & $-5.4 \pm 2.1$ & $-6.3 \pm 3.5$ & 0.091 & 0.350 & 0.582 \\
\hline & Internal rotation peak & Long & $5.5 \pm 7.4$ & $4.6 \pm 7.6$ & $6.7 \pm 7.6$ & $4.1 \pm 7.5$ & 0.651 & 0.438 & 0.179 \\
\hline & & Short & $5.1 \pm 8.9$ & $3.5 \pm 7.0$ & $5.1 \pm 7.5$ & $2.8 \pm 7.4$ & 0.614 & 0.374 & 0.609 \\
\hline & External rotation peak & Long & $-2.5 \pm 6.8$ & $-3.0 \pm 7.3$ & $-1.2 \pm 6.2$ & $-3.7 \pm 7.4$ & 0.603 & 0.482 & 0.124 \\
\hline & & Short & $-2.0 \pm 8.3$ & $-4.4 \pm 7.6$ & $-2.2 \pm 7.0$ & $-5.1 \pm 7.3$ & 0.478 & 0.243 & 0.691 \\
\hline \multirow[t]{12}{*}{ Knee } & Flexion peak & Long & $65.0 \pm 3.3$ & $65.0 \pm 4.4$ & $63.9 \pm 3.1$ & $64.4 \pm 4.5$ & $0.003^{\star}$ & 0.834 & 0.319 \\
\hline & & Short & $62.7 \pm 3.4$ & $63.0 \pm 4.2$ & $62.0 \pm 3.3$ & $63.0 \pm 4.3$ & 0.256 & 0.594 & 0.24 \\
\hline & Extension peak & Long & $-3.6 \pm 3.6$ & $-2.7 \pm 4.3$ & $-4.1 \pm 4.0$ & $-2.8 \pm 4.1$ & 0.193 & 0.369 & 0.425 \\
\hline & & Short & $-4.6 \pm 3.4$ & $-3.5 \pm 3.9$ & $-4.6 \pm 3.7$ & $-3.4 \pm 3.9$ & 0.688 & 0.308 & 0.644 \\
\hline & Adduction peak & Long & $6.7 \pm 5.6$ & $6.2 \pm 5.5$ & $7.4 \pm 6.5$ & $5.7 \pm 5.3$ & 0.828 & 0.505 & 0.262 \\
\hline & & Short & $5.8 \pm 5.3$ & $5.3 \pm 4.9$ & $5.5 \pm 4.9$ & $4.6 \pm 4.6$ & 0.314 & 0.635 & 0.636 \\
\hline & Abduction peak & Long & $-2.8 \pm 3.7$ & $-2.9 \pm 4.1$ & $-2.3 \pm 4.3$ & $-2.9 \pm 3.6$ & 0.286 & 0.783 & 0.249 \\
\hline & & Short & $-3.7 \pm 2.8$ & $-3.0 \pm 4.3$ & $-2.9 \pm 2.8$ & $-3.4 \pm 4.3$ & 0.528 & 0.913 & 0.162 \\
\hline & Internal rotation peak & Long & $-16.6 \pm 6.2$ & $-15.3 \pm 9.2$ & $-18.3 \pm 7.6$ & $-15.3 \pm 8.9$ & 0.218 & 0.400 & 0.176 \\
\hline & & Short & $-15.1 \pm 8.2$ & $-12.7 \pm 7.1$ & $-14.5 \pm 7.9$ & $-13.0 \pm 8.2$ & 0.794 & 0.394 & 0.587 \\
\hline & External rotation peak & Long & $-28.6 \pm 9.1$ & $-26.7 \pm 9.1$ & $-30.3 \pm 10.2$ & $-26.7 \pm 8.5$ & 0.233 & 0.319 & 0.199 \\
\hline & & Short & $-26.5 \pm 8.9$ & $-24.0 \pm 7.8$ & $-25.4 \pm 8.3$ & $-24.7 \pm 8.1$ & 0.831 & 0.522 & 0.217 \\
\hline \multirow[t]{12}{*}{ Ankle } & Dorsiflexion peak & Long & $3.2 \pm 4.9$ & $3.8 \pm 3.8$ & $2.7 \pm 4.6$ & $4.0 \pm 4.2$ & 0.523 & 0.449 & 0.207 \\
\hline & & Short & $0.9 \pm 4.2$ & $2.5 \pm 3.3$ & $2.0 \pm 3.6$ & $3.6 \pm 2.9$ & $0.001^{*}$ & 0.124 & 0.886 \\
\hline & Plantar flexion peak & Long & $-18.2 \pm 7.9$ & $-16.1 \pm 5.1$ & $-18.4 \pm 7.3$ & $-16.5 \pm 5.5$ & 0.367 & 0.291 & 0.869 \\
\hline & & Short & $-21.4 \pm 8.4$ & $-18.2 \pm 6.1$ & $-20.9 \pm 7.8$ & $-17.5 \pm 6.2$ & 0.092 & 0.120 & 0.706 \\
\hline & Inversion peak & Long & $12.4 \pm 3.9$ & $11.7 \pm 3.4$ & $13.0 \pm 4.0$ & $11.8 \pm 3.6$ & 0.068 & 0.390 & 0.251 \\
\hline & & Short & $14.8 \pm 4.9$ & $12.4 \pm 3.8$ & $15.0 \pm 4.0$ & $12.7 \pm 3.5$ & 0.402 & 0.056 & 0.891 \\
\hline & Eversion peak & Long & $4.8 \pm 3.6$ & $5.4 \pm 4.4$ & $5.1 \pm 4.1$ & $5.7 \pm 4.2$ & 0.324 & 0.660 & 0.87 \\
\hline & & Short & $6.4 \pm 4.2$ & $6.2 \pm 3.8$ & $6.6 \pm 4.5$ & $6.1 \pm 3.4$ & 0.896 & 0.793 & 0.557 \\
\hline & Internal rotation peak & Long & $-2.4 \pm 7.9$ & $-6.1 \pm 5.1$ & $-3.1 \pm 7.7$ & $-6.1 \pm 6.1$ & 0.350 & 0.092 & 0.360 \\
\hline & & Short & $-3.0 \pm 5.0$ & $-3.2 \pm 5.6$ & $-2.9 \pm 5.0$ & $-3.7 \pm 5.5$ & 0.359 & 0.768 & 0.299 \\
\hline & External rotation peak & Long & $-14.5 \pm 7.5$ & $-16.1 \pm 6.0$ & $-15.4 \pm 7.5$ & $-16.3 \pm 6.8$ & 0.119 & 0.559 & 0.336 \\
\hline & & Short & $-13.1 \pm 5.5$ & $-13.3 \pm 6.0$ & $-13.2 \pm 5.0$ & $-13.6 \pm 6.0$ & 0.330 & 0.877 & 0.665 \\
\hline
\end{tabular}

*Significant difference $(p<0.05)$. 
TABLE 5 | Localization of pain of the subjects included in each group.

\begin{tabular}{|c|c|c|c|c|}
\hline & \multicolumn{2}{|c|}{$G_{L L D} \leq 1 \mathrm{~cm}$} & \multicolumn{2}{|c|}{$G_{L L D>1 \mathrm{~cm}}$} \\
\hline & \multicolumn{2}{|c|}{$n=16$} & \multicolumn{2}{|c|}{$n=30$} \\
\hline Low back pain & \multicolumn{2}{|c|}{9} & \multicolumn{2}{|c|}{17} \\
\hline Hip pain & \multicolumn{2}{|l|}{4} & \multicolumn{2}{|c|}{3} \\
\hline Knee pain & \multicolumn{2}{|c|}{3} & \multicolumn{2}{|c|}{4} \\
\hline \multirow[t]{3}{*}{ Ankle pain } & \multicolumn{2}{|c|}{0} & \multicolumn{2}{|c|}{6} \\
\hline & \multicolumn{2}{|c|}{$G_{L L D} \leq 1 \mathrm{~cm}$} & \multicolumn{2}{|c|}{$G_{L L D>1 \mathrm{~cm}}$} \\
\hline & Without OI & With OI & Without OI & With ol \\
\hline Visual analog scale scores & $5.9 \pm 1.8$ & $1.7 \pm 2.1$ & $5.7 \pm 2.6$ & $2.0 \pm 2.5$ \\
\hline
\end{tabular}

longer leg (Walsh et al., 2000; Resende et al., 2016) and the increase in the plantar flexion on the shorter leg during stance phase are also in line with the results of previous studies (Song et al., 1997; Walsh et al., 2000; Aiona et al., 2015; Resende et al., 2016). The results of the present study showed that use of an OI significantly increased peak dorsiflexion in the shorter leg and decreased both peak dorsiflexion and peak plantar flexion in the longer leg (independently from the group). These changes likely contributed to the improvement in ankle gait symmetry shown by the SI. The kinematic alterations found at the pelvis (frontal plane) and ankle (sagittal plane) during gait without the OI are typical compensatory strategies that functionally lengthen the shorter limb and shorten the longer limb (Resende et al., 2016). The findings of the present study indicate that the OI reduced the need for such strategies.

The results of several studies in the literature contrast with those of the present study: some studies found no effect of an OI on joint kinematics during gait in mild LLD (Bandy and Sinning, 1986; Goel et al., 1997), although effects were found for moderate and severe LLD (Bangerter et al., 2019). These different results could be due to differences in the study methodologies. First, the sample sizes in both the studies by Bandy and Sinning (1986) and Goel et al. (1997) were smaller than that of the present study, and they may have been underpowered. The studies also analyzed different variables and used different types of LLD correction: Bandy and Sinning (1986) used a heel lift, while Goel et al. (1997) used a shoe lift. Although Bandy and Sinning (1986) found that the heel lift seemed to bring about more symmetrical movement, another study (Khamis and Carmeli, 2017) found that a heel lift was insufficient to affect the entire stance phase of the gait cycle.

The positive effect of the OI on symmetry found in the present study for both mild and very mild LLD was further supported by the significant reduction in pain: use of the OI immediately and significantly reduced pain in both groups, with no betweengroup differences. These results are clinically important since the biomechanical, postural, and functional changes caused by LLD have been shown to alter joint angles (Gurney, 2002; Campbell et al., 2018), leading to low back pain, scoliosis, pelvic and sacral misalignments, hip and knee osteoarthritis, and even stress fractures of the lower limbs (Gurney, 2002; Kendall et al., 2014; Campbell et al., 2018; Beeck et al., 2019). The reduction of pelvic obliquity with the OI likely reduced muscle overactivity (Mannello, 1992) and the distribution forces on the spinal joints, thus reducing pain (Defrin et al., 2005; Golightly et al., 2007) and potentially reducing the development of pathology in the long-term (Giles, 1981; Giles and Taylor, 1982; Cummings et al., 1993). LLD has been implicated in hip and knee pain due to inadequate distribution of mechanical loads (McCaw and Bates, 1991; McWilliams et al., 2013). Indeed, LLD results in excessive and uneven loading on the hip and/or knee and also on the mobile segments of the lumbar belt (Murray and Azari, 2015). Improvement of the gait symmetry of the pelvis in the frontal plane and of the ankle in the sagittal plane could improve the distribution of mechanical loads throughout the lower limb and thus significantly reduce associated pain. These results are in line with the current literature, which shows that OI can reduce pain in subjects with mild LLD (Defrin et al., 2005; Golightly et al., 2007; Menez et al., 2020). In addition, as reported by Defrin et al. (2005) who evaluated only the effect of insoles on low back pain, very mild LLD can be the source of pain, and the shoe inserts can be a suitable therapeutic solution to reduce pain. Longitudinal studies are now required to determine the long-term effect of OI on chronic pain.

As found in a previous study (Resende et al., 2016), peak hip flexion was increased, and peak hip abduction was decreased on the side of the shorter leg during stance without the OI. Although these deviations were reduced with the OI, the SI did not change for these joints in either group, suggesting that the use of the OI was insufficient to correct them. This was also the case for ankle inversion-eversion during stance on the side of the longer leg, as well as the deviations found in pelvic, knee, and ankle motion during swing phase (Table 4). Several factors could explain the lack of normalization of these kinematic parameters with the OI. First, it is possible that the trim magnitude of the OI was too low (the correction applied was $50 \%$ of the magnitude of the LLD). Clinically, it may be worthwhile to carry out repeated kinematic analyses with OI of different magnitudes until all joint kinematics become symmetrical left-right. Second, and more likely, the compensatory strategies for the LLD were well-established in these individuals with anatomical LLD, and it is thus unsurprising that their strategies could not be changed in a single session of walking with OI. Moreover, the compensatory biomechanical strategies used by subjects with LLD are complex (Menez et al., 2020). Further studies are required to assess the longer-term effects of OI on gait kinematics.

The present study adds to the current body of literature on LLD by providing more extensive kinematic data. Together, these results confirm that even mild LLD alters gait kinematics.

However, new studies are essential to continue to optimize the management of subjects in the field of podiatry. These future studies will need to consider some of the limitations identified throughout this work. This study was not a randomized controlled trial, and neither the examiner nor the participants were blinded that can lead to a placebo effect of OI for pain assessment. For pain analysis, we have adapted to the field conditions using a visual analog scale. In the clinical and research field, the visual analog scale is widely used and accepted (Hayashi et al., 2015). We have tried to limit the potential bias that comes 
with the subjective declaration of the visual analog scale by asking subjects to be as truthful as possible in their evaluations. Future trials should be blinded to reduce this potential bias. On the other hand, more precise questionnaires should be implemented in order to situate and define pain more accurately, as some previous studies have done (Defrin et al., 2005; Golightly et al., 2007). For the SI, we can observe (Table 2) that some SIs are higher for the $G_{L L D \leq 1 \mathrm{~cm}}$ than for the $G_{L L D>1 \mathrm{~cm}}$ (especially in the transverse plane). A limitation of the SI is the potential for artificial inflation. This inflation can occur when the observed variables have small changes that can lead to large changes in the SI (Cabral et al., 2016). Finally, it would be interesting to highlight other aspects of motion analysis that could complete and explain some of our results. Indeed, with a kinetic approach, Aiona et al. (2015) and Song et al. (1997) put forward a more important mechanical work of the long leg, therefore possibly a more important articular, muscular, and tendinous work, which was confirmed by Perttunen et al. (2004). In future studies, it would be interesting to supplement the kinematic data with kinetic variables coupled with electromyographic analysis to refine the understanding of the effect of OI on changes in the biomechanics of locomotion.

\section{CONCLUSION}

This study contributes to a better understanding of the effect of OI on gait kinematics observed in subjects with mild LLD. OI immediately significantly improved the articular symmetry of the pelvis in the frontal plane and of the ankle in the sagittal plane, regardless of the height of LLD (i.e., LLD $\leq 1 \mathrm{~cm}$ vs. LLD $>1 \mathrm{~cm}<3 \mathrm{~cm}$ ). In addition, our study confirms that OI significantly reduces pain in subjects with mild LLD. Therefore, we can recommend treatment of mild LLD with OI, even when LLD $\leq 1 \mathrm{~cm}$. This study contributes to a better understanding of the effect of OI on gait kinematics in subjects with mild LLD and provides valuable information for clinicians. Nevertheless, future studies could complement this research and shed new light on this research subject.

\section{REFERENCES}

Aiona, M., Do, K. P., Emara, K., Dorociak, R., and Pierce, R. (2015). Gait patterns in children with limb length discrepancy. J. Pediatr. Orthop. 35, 280-284. doi: 10.1097/BPO.0000000000000262

Bandy, W. D., and Sinning, W. E. (1986). Kinematic effects of heel lift use to correct lower limb length differences. J. Orthop. Sports Phys. Ther. 7, 173-179. doi: 10.2519/jospt.1986.7.4.173

Bangerter, C., Romkes, J., Lorenzetti, S., Krieg, A. H., Hasler, C. -C., Brunner, R., et al. (2019). What are the biomechanical consequences of a structural leg length discrepancy on the adolescent spine during walking? Gait Posture 68, 506-513. doi: 10.1016/j.gaitpost.2018.12.040

Beattie, P., Isaacson, K., Riddle, D. L., and Rothstein, J. M. (1990). Validity of derived measurements of leg-length differences obtained by use of a tape measure. Phys. Ther. 70, 150-157. doi: 10.1093/ptj/70.3.150

Beeck, A., Quack, V., Rath, B., Wild, M., Michalik, R., Schenker, H., et al. (2019). Dynamic evaluation of simulated leg length inequalities and their effects on the musculoskeletal apparatus. Gait Posture 67, 71-76. doi: 10.1016/j.gaitpost.2018.09.022

\section{DATA AVAILABILITY STATEMENT}

The raw data supporting the conclusions of this article will be made available by the authors, without undue reservation.

\section{ETHICS STATEMENT}

Ethical review and approval was not required for the study on human participants in accordance with the local legislation and institutional requirements. The patients/participants provided their written informed consent to participate in this study.

\section{AUTHOR CONTRIBUTIONS}

All of the named authors meet the criteria for authorship. $\mathrm{CM}$ was the principal investigator. He co-designed the study, over-saw the project, contributed to the interpretation of the data, revised the study report for intellectual content, and approved the version to be published. JC co-designed the study, contributed to the interpretation of the data, coordinate the project, contributed to the drafting of the manuscript, revised it for intellectual content, and approved the version to be published. ML'H co-designed the study, coordinated the project, revised the report for intellectual content, and approved the version to be published.

\section{FUNDING}

This study was funded as a Ph.D. grant by the French National Association of Research and Technology (grant CIFRE $\mathrm{n}^{\circ} 2016 / 1120$ ) and Normandie Univ, UNIROUEN, CETAPS, 76000 Rouen, France.

\section{SUPPLEMENTARY MATERIAL}

The Supplementary Material for this article can be found online at: https://www.frontiersin.org/articles/10.3389/fspor. 2020.579152/full\#supplementary-material

Brady, R. J., Dean, J. B., Skinner, T. M., and Gross, T. M. (2003). Limb length inequality: clinical implications for assessment and intervention. J. Orthop. Sports Phys. Ther. 33, 221-234. doi: 10.2519/jospt.2003.33.5.221

Cabral, S., Resende, R. A., Clansey, A. C., Deluzio, K. J., Selbie, W. S., and Veloso, A. P. (2016). A global gait asymmetry index. J. Appl. Biomech. 32, 171-177. doi: $10.1123 /$ jab.2015-0114

Campbell, T. M., Ghaedi, B. B., Ghogomu, E. T., and Welch, V. (2018). Shoe lifts for leg length discrepancy in adults with common painful musculoskeletal conditions: a systematic review of the literature. Arch. Phys. Med. Rehabil. 99:981-993.e2. doi: 10.1016/j.apmr.2017.10.027

Cappozzo, A., Catani, F., Della Croce, U., and Leardini, A. (1995). Position and orientation in space of bones during movement: anatomical frame definition and determination. Clin Biomech. 10, 171-178. doi: 10.1016/0268-0033(95)91394-T

Cummings, G., Scholz, J. P., and Barnes, K. (1993). The effect of imposed leg length difference on pelvic bone symmetry. Spine 18, 368-373. doi: 10.1097/00007632-199303000-00012

Defrin, R., Benyamin, S. B., Aldubi, R. D., and Pick, C. G. (2005). Conservative correction of leg-length discrepancies of $10 \mathrm{~mm}$ or less for the relief 
of chronic low back pain. Arch. Phys. Med. Rehabil. 86, 2075-2080. doi: 10.1016/j.apmr.2005.06.012

Friberg, O. (1982). Leg length asymmetry in stress fractures. A clinical and radiological study. J. Sports Med. Phys. Fitness 22, 485-488.

Friberg, O. (1984). Leg length inequality and low back pain. Lancet 324:1039. doi: 10.1016/S0140-6736(84)91135-8

Giles, L. G. F. (1981). Lumbosacral facetal “joint angles” associated with leg length inequality. Rheumatology 20, 233-238. doi: 10.1093/rheumatology/20.4.233

Giles, L. G. F., and Taylor, J. R. (1982). Lumbar spine structural changes associated with leg length inequality. Spine 7, 159-162. doi: 10.1097/00007632-198203000-00011

Goel, A., Loudon, J., Nazare, A., Rondinelli, R., and Hassanein, K. (1997). Joint moments in minor limb length discrepancy: a pilot study. Am. J. Orthop. 26, 852-856

Golightly, Y. M., Tate, J. J., Burns, C. B., and Gross, M. T. (2007). Changes in pain and disability secondary to shoe lift intervention in subjects with limb length inequality and chronic low back pain: a preliminary report. J. Orthop. Sports Phys. Ther. 37, 380-388. doi: 10.2519/jospt.2007.2429

Grood, E. S., and Suntay, W. J. (1983). A joint coordinate system for the clinical description of three-dimensional motions: application to the knee. J. Biomech. Eng. 105, 136-144. doi: 10.1115/1.3138397

Gurney, B. (2002). Leg length discrepancy. Gait Posture 15, 195-206. doi: 10.1016/S0966-6362(01)00148-5

Harvey, W. F. (2010). Association of leg-length inequality with knee osteoarthritis: a cohort study. Ann. Intern. Med. 152, 287-295. doi: 10.7326/0003-4819-152-5-201003020-00006

Hayashi, K., Ikemoto, T., Ueno, T., Arai, Y.-C. P., Shimo, K., Nishihara, M., et al. (2015). Regional differences of repeatability on visual analogue scale with experimental mechanical pain stimuli. Neurosci. Lett. 585:67-71. doi: 10.1016/j.neulet.2014.11.032

Jamaluddin, S., Sulaiman, A. R., Kamarul Imran, M., Juhara, H., Ezane, M. A., and Nordin, S. (2011). Reliability and accuracy of the tape measurement method with a nearest reading of $5 \mathrm{Mm}$ in the assessment of leg length discrepancy. Singapore Med. J. 52, 681-684.

Junk, S., Terjesen, T., Rossvoll, I., and $\mathrm{Bra}^{\circ}$ ten, M. (1992). Leg length inequality measured by ultrasound and clinical methods. Eur. J. Radiol. 14, 185-188. doi: 10.1016/0720-048X(92)90083-L

Kaufman, K. R., Miller, L. S., and Sutherland, D. H. (1996). Gait asymmetry in patients with limb-length inequality. J. Pediatr. Orthop. 16, 144-150. doi: 10.1097/01241398-199603000-00002

Kendall, J. C., Bird, A. R., and Azari, M. F. (2014). Foot posture, leg length discrepancy and low back pain - Their relationship and clinical management using foot orthoses - an overview. Foot 24, 75-80. doi: 10.1016/j.foot.2014.03.004

Khamis, S., and Carmeli, E. (2017). Relationship and significance of gait deviations associated with limb length discrepancy: a systematic review. Gait Posture 57, 115-123. doi: 10.1016/j.gaitpost.2017.05.028

Khamis, S., and Carmeli, E. (2018). The effect of simulated leg length discrepancy on lower limb biomechanics during gait. Gait Posture 61, 73-80. doi: 10.1016/j.gaitpost.2017.12.024

Leardini, A., Sawacha, Z., Paolini, G., Ingrosso, S., Nativo, R., and Benedetti, M. G. (2007). A new anatomically based protocol for gait analysis in children. Gait Posture 26, 560-571. doi: 10.1016/j.gaitpost.2006.12.018

Mannello, D. M. (1992). Leg length inequality. J. Manipulative Physiol. Ther. $15,576-590$.

McCaw, S. T., and Bates, B. T. (1991). Biomechanical implications of mild leg length inequality. Br. J. Sports Med. 25, 10-13. doi: 10.1136/bjsm.25.1.10

McWilliams, A. B., Grainger, A. J., O'Connor, P. J., Redmond, A. C., Stewart, T. D., and Stone, M. H. (2013). A review of symptomatic leg length inequality following total hip arthroplasty. HIP Int. 23, 6-14. doi: 10.5301/HIP.2013.10631

Menez, C., Coquart, J., Dodelin, D., Tourny, C., and L'Hermette, M. (2020). Effects of orthotic insoles on gait kinematics and low back pain in subjects with mild leg length discrepancy: a pilot study. J. Am. Podiatr. Med. Assoc. doi: 10.7547/18-093. [Epub ahead of print].
Moseley, C. F. (1996). Leg Length Discrepancy and Angular Deformity of the Lower Limbs. Lovell and Winter's Pediatric Orthopedics. 4th edn. Philadelphia, PA: Lippincott-Raven, 849-901.

Murray, K. J., and Azari, M. F. (2015). Leg length discrepancy and osteoarthritis in the knee, hip and lumbar spine. J. Can. Chiropr. Assoc. 59, 226-237.

Neelly, K., Wallmann, H. W., and Backus, C. J. (2013). Validity of measuring leg length with a tape measure compared to a computed tomography scan. Physiother. Theory Pract. 29, 487-492. doi: 10.3109/09593985.2012.755589

Perttunen, J. R., Anttila, E., Södergård, J., Merikanto, J., and Komi, P. V. (2004). Gait asymmetry in patients with limb length discrepancy. Scand. J. Med. Sci. Sports 14, 49-56. doi: 10.1111/j.1600-0838.2003.00307.x

Reid, D. C., and Smith, B. (1984). Leg length inequality: a review of etiology and management. Physiother Canada 36, 177-182.

Resende, R. A., Kirkwood, R. N., Deluzio, K. J., Cabral, S., and Fonseca, S. T. (2016). Biomechanical strategies implemented to compensate for mild leg length discrepancy during gait. Gait Posture 46:147-153. doi: 10.1016/j.gaitpost.2016.03.012

Robinson, R. O., Herzog, W., and Nigg, B. M. (1987). Use of force platform variables to quantify the effects of chiropractic manipulation on gait symmetry. J. Manipulative Physiol. Ther 10, 172-176.

Seeley, M. K., Umberger, B. R., Clasey, J. L., and Shapiro, R. (2010). The relation between mild leg-length inequality and able-bodied gait asymmetry. J. Sports Sci. Med. 9, 572-579.

Song, K. M., Halliday, S. E., and Little, D. G. (1997). The effect of limb-length discrepancy on gait. J. Bone Joint Surg. 79:1690-1698. doi: 10.2106/00004623-199711000-00011

Specht, D. L., and De, K. B. (1991). Anatomical leg length inequality, scoliosis and lordotic curve in unselected clinic patients. J. Manipulative Physiol. Ther 14, 368-375.

Tallroth, K., Ristolainen, L., and Manninen, M. (2017). Is a long leg a risk for hip or knee osteoarthritis? Acta Orthop. 88, 512-515. doi: 10.1080/17453674.2017.1348066

Von Elm, E., Altman, D. G., Egger, M., Pocock, S. J., Gøtzsche, P. C., Vandenbroucke, J. P., et al. (2014). The Strengthening the Reporting of Observational Studies in Epidemiology (STROBE) Statement: guidelines for reporting observational studies. Int. J. Surg. 12, 1495-1499. doi: 10.1016/j.ijsu.2014.07.013

Walsh, M., Connolly, P., Jenkinson, A., and O’Brien, T. (2000). Leg length discrepancy - an experimental study of compensatory changes in three dimensions using gait analysis. Gait Posture 12, 156-161. doi: 10.1016/S0966-6362(00)00067-9

White, S. C., Gilchrist, L. A., and Wilk, B. E. (2004). Asymmetric limb loading with true or simulated leg-length differences. Clin. Orthop. Relat. Res. 421, 287-292. doi: 10.1097/01.blo.0000119460.33630.6d

Wu, G., and Cavanagh, P. R. (1995). ISB recommendations for standardization in the reporting of kinematic data. J. Biomech. 28, 1257-1261. doi: 10.1016/0021-9290(95)00017-C

Wu, G., Siegler, S., Allard, P., Kirtley, C., Leardini, A., Rosenbaum, D., et al. (2002). ISB recommendation on definitions of joint coordinate system of various joints for the reporting of human joint motion-Part I: ankle, hip, and spine. J. Biomech. 35, 543-548. doi: 10.1016/S0021-9290(01)0 0222-6

Conflict of Interest: The authors declare that the research was conducted in the absence of any commercial or financial relationships that could be construed as a potential conflict of interest.

Copyright (c) $2020 \mathrm{Menez}$, L'Hermette and Coquart. This is an open-access article distributed under the terms of the Creative Commons Attribution License (CC BY). The use, distribution or reproduction in other forums is permitted, provided the original author(s) and the copyright owner(s) are credited and that the original publication in this journal is cited, in accordance with accepted academic practice. No use, distribution or reproduction is permitted which does not comply with these terms. 